\title{
EDUCAÇÃO, DEMOCRACIA E LIBERDADE: UMA VISÃO LIBERAL E REPUBLICANA
}

\author{
Alana Tiosso* \\ Marcos Antônio Striquer ${ }^{* *}$
}

\section{RESUMO}

Este artigo versa sobre a restrição de liberdade na educação. Analisa-se o conceito de liberdade e de cidadania por meio da teoria liberal e republicana, a fim de verificar qual o modelo de educação condiz com um Estado Democrático de Direito. Utiliza-se o método dedutivo e a revisão bibliográfica. $O$ ensino pela perspectiva liberal apresenta-se neutro de imposições ideológicas, porém inviável de ser aplicado. A educação pelo viés republicano contém cargas valorativas, mas apresenta-se condizente com os preceitos constitucionais de uma democracia, pois contribui para o pluralismo de ideias e para a formação de cidadãos com virtudes cívicas.

Palavras-chave: Democracia. Educação. Liberdade. Liberalismo. Republicanismo.

\section{EDUCATION, DEMOCRACY AND FREEDOM: A LIBERAL AND REPUBLICAN VISION}

\begin{abstract}
This article is about the restriction of freedom in education. The concept of freedom and citizenship are analyzed through liberal and republican theories, in order to verify which model of education corresponds to a Democratic State of Law. It was used the deductive method and bibliographic review. Teaching from the liberal perspective is neutral of ideology, but impracticable to be applied. Education by the Republican bias contains valuation, but it demonstrates itself in accordance with the constitutional precepts of a democracy, and it contributes to the pluralism of ideas and to the formation of citizens with civic virtues.
\end{abstract}

Keywords: Democracy. Education. Freedom. Liberalism. Republicanism.

\section{INTRODUÇÃO}

Atualmente, diante dos recentes debates na política, discutem-se a liberdade na educação e a intervenção estatal no ensino. As interferências surgem na estipulação da base

\footnotetext{
Mestranda em Direito Negocial pela Universidade Estadual de Londrina (UEL). Especialista em Direito Constitucional pelo Instituto de Direito Constitucional e Cidadania (IDCC). Especialista em Direito Previdenciário pela Universidade Estadual de Londrina (UEL). E-mail: alanatiosso@ hotmail.com.

** Doutor e Mestre em Direito pela Pontifícia Universidade Católica de São Paulo (PUC). Professor titular da Universidade do Oeste Paulista, da Universidade Norte do Paraná e Professor da Universidade Estadual de Londrina, atuando nesta Instituição como docente permanente do Programa de Mestrado em Direito Negocial. Email: marcosstriquer@uol.com.br
} 
nacional comum curricular, com as disciplinas selecionadas, bem como nos princípios éticos, políticos que direcionam a educação brasileira para a formação dos cidadãos. Assim, desenvolve-se a temática sobre o limite do que pode ou não ser tratado entre professores e alunos, e a influência dessas discussões em temas como política, valores e ideologias pessoais.

O problema a ser apresentado neste estudo versa sobre a restrição de liberdade na educação. Para isso, discute-se a interferência do governo na liberdade de ensinar do professor na educação escolar, com o objetivo de gerar uma reflexão a respeito da atuação política e sua influência no ensino, o qual se reflete na formação dos cidadãos. O método utilizado é o dedutivo, a partir de uma análise bibliográfica sobre a liberdade, a democracia e a educação.

A hipótese consiste em uma atuação estatal que possa ser capaz de garantir a promoção da liberdade na educação, ao incentivar uma democracia participativa e contestatória, com a apresentação de valores para a construção da cidadania, e para desenvolver um povo crítico e consciente de sua função na sociedade. $\mathrm{O}$ agir do Estado deve garantir as liberdades individuais e contribuir para um processo educacional livre e democrático.

O texto estrutura-se em três partes, além desta introdução. Na primeira parte, expõese a importância da democracia participativa e o envolvimento dos cidadãos na política. $\mathrm{Na}$ segunda, discorre-se sobre o modelo de liberdade na perspectiva da teoria liberal de Isaiah Berlin e na visão republicana de Philip Pettit. Ambas as teorias são expostas também por estudos feitos por Cesar Augusto Ramos.

Na terceira parte, apresenta-se a visão liberal de Milton Friedman e Friedrich Hayek, segundo a qual o ideal de educação deve ser isento de imposições ideológicas; assim como a visão de Stuart Mill, que remete à possibilidade de serem ensinados os mais diversos temas na escola, desde que expostas aos alunos as suas múltiplas vertentes. Após, aborda-se a liberdade na educação na visão liberal e republicana e suas interferências na formação dos cidadãos, a fim de compreender o modelo mais adequado referente à liberdade de ensinar em um Estado democrático de direito.

\section{A DEMOCRACIA PARTICIPATIVA}


A Constituição da República Federativa do Brasil de 1988, recentemente, em 05 de outubro de 2018, completou 30 anos desde a sua promulgação, e teve um papel relevante no processo democrático brasileiro. Após um período ditatorial, surgiu com a previsão da garantia de direitos fundamentais e individuais, pactuando o papel da cidadania. Dentre esses direitos, o Artigo $5^{\circ}$, caput, prevê a liberdade como direito fundamental de todos. O Artigo $6^{\circ}$, caput, disciplina os direitos sociais, entre eles, o direito à educação, o qual deve ser pautado pelos princípios que versam sobre a liberdade de aprender, ensinar, pesquisar e divulgar o pensamento (Art. $206^{\circ}$, II) e sobre o pluralismo de ideias e de concepções pedagógicas (Art. $206^{\circ}$, III).

A democracia política e a cidadania são fatores de inclusão social por ações afirmativas na busca de igualdade e ampliação de direitos. O nexo de democracia com o poder e a participação do povo nas tomadas de decisões na sociedade foi rompido. A soberania popular pela democracia participativa somente se realiza com o envolvimento dos homens nas deiberaçoes nos assuntos que envolvem a sociedade. Diante disso, percebe-se que os direitos individuais e sociais sofreram redução na sua garantia.

Nessa perspectiva, a fim de restaurar o estado de bem-estar social, os povos carecem de retomar os preceitos da democracia participativa para focar na liberdade, no desenvolvimento da sociedade e da própria democracia. A democracia participativa baseia-se nos direitos fundamentais positivados na Carta Magna (BONAVIDES, 2001, p. 9.).

$\mathrm{Na}$ concepção de Aristóteles, o homem é um animal político, e sua natureza se justifica pela necessidade de viver em comunidade. A política justa revela-se como um meio para diminuir as desigualdades existentes no ambiente coletivo. Em um espaço público, os homens decidem as questões da cidade e do modo de convivência entre eles, o que é fator determinante da forma de poder e do exercício da política. (CHAUI, 2007, p. 27).

Para Chaui (2007, p. 27), entre os principais aspectos da ausência de participação do indivíduo na política está a 'destruição da esfera da opinião pública', que perde força e deixa de ser o local de discussões, debates sobre economia, cultura, política e assuntos sociais e passa a ser um campo de preferências individuais. Com a existência do marketing político fornecido pelas mídias, a condução da política dirige-se aos interesses da sociedade de consumo, com o foco em hábitos, costumes, religião e valores, e assim ocorrem o desvio de atenção de temas relevantes para o progresso da sociedade e o afastamento do exercício da cidadania. 
Os meios de comunicação

[...] legitimam as mais absurdas políticas de governo, contrariando o interesse nacional e destruindo as células morais do ente cívico que é a polis", anula-se "o livre raciocínio, a livre consciência do ser político, rebaixando a cidadão nominal, [...] ostentando a imagem da pseudo democracia e do pseudo regime representativo. (BONAVIDES, 2001, p. 12)

$\mathrm{Na}$ ideia de ideologia de competência, somente pessoas especialistas no assunto devem tratar de temas que envolvem a política. A participação do cidadão restringe-se ao voto, sob o argumento de que nem todos os indivíduos possuem capacidade para deliberar temas da política. Nessa perspectiva, há o incentivo ao esvaziamento da cidadania e do envolvimento do homem na resolução de problemas na comunidade e, consequentemente, há a redução da garantia dos direitos básicos inerentes ao ser humano (CHAUI, 2007, p. 27).

A democracia consubstancia-se como a forma de governo, a vida social e política, em que os homens são livres e autores das leis que seguem. As ideias múltiplas que permeiam a sociedade podem ser expostas e utilizadas para enriquecimento do debate público, a fim de instituir políticas públicas e medidas de atendimento à carência da sociedade e dos homens como direitos. A democracia manifesta-se como política por meio da ação social para dirigir, controlar e modificar o exercício da atividade estatal e o poder do governo com as leis e as instituições (CHAUI, 2007, p. 53).

O processo de formação de opinião na democracia engloba o exercício ativo do povo nas tomadas de decisão e a oportunidade de homens comuns serem eleitos para representarem a população. Para a conjuntura da democracia participativa, é preciso um enfoque na educação para a formação da cidadania nos indivíduos. Uma democracia não funciona na sua plenitude com cidadãos analfabetos. A educação exerce papel fundamental na concretização de princípios democráticos, sendo, portanto, a educação e a democracia indissociáveis. O ambiente de ensino deve ser livre e ter como base o respeito mútuo entre alunos e professores, a construção do diálogo e a liberdade no desenvolvimento de ideias.

Posto isso, para compreender a liberdade no ensino, convém discorrer a respeito da liberdade no liberalismo e no republicanismo, bem como sobre o conceito de cidadania em ambas as vertentes, a fim de, posteriormente, analisar a educação livre, pautada na construção da cidadania dos alunos. 


\section{A LIBERDADE NO LIBERALISMO E NO REPUBLICANISMO}

\subsection{A liberdade no modelo liberal}

A liberdade, para Berlin (1969, p. 136), possui diversos sentidos. Em seu texto, “os quatro ensaios sobre a liberdade", o autor propõe examinar o conceito da palavra liberdade em dois sentidos. Um deles é a liberdade individual ou institucional, a qual intitula como liberdade negativa, e o outro é a liberdade no seu sentido positivo.

O sentido negativo de liberdade demonstra-se como ausência de impedimentos. O conceito de ser livre relaciona-se com não sofrer a interferência de outrem e fazer o que está permitido por lei. Para Berlin (1969, p. 136), [...] "alguém é livre na medida em que nenhum outro homem ou nenhum grupo de homens interfere nas atividades desse alguém". A liberdade positiva requer mais que uma ausência de interferência, ela origina-se no desejo do indivíduo de ser senhor de si mesmo, e não de sofrer influências externas por atos de outros homens. (BERLIN, 1969, p. 142).

A partir disso, pode-se entender que a liberdade política se solidifica na esfera de exercício político do homem, sem que sofra restrições por seus pares. A liberdade é imanente a cidadania.

Nesse aspecto, a liberdade e o direito podem ser fundamentados pelo princípio da justiça que subordina a política como instrumento para a realização e a proteção dos direitos individuais; bem como pela associação do direito com as relações de mútuo reconhecimento e aos deveres da cidadania, com vistas à proteção do bem comum da comunidade, cujo escopo maior consolida-se na liberdade como não dominação (RAMOS, 2011, p. 45).

O liberalismo, como modo de atuação do homem na sua dimensão política, baseia-se na liberdade individual, na propriedade privada e nos direitos subjetivos. Assim, visa à atuação de um Estado limitado e à defesa dos direitos humanos. A cidadania liberal, na perspectiva de Ramos (2006, p. 79), pode ser compreendida como a [...] "intitulação de direitos e o seu valor normativo é apreciado como mero meio para a realização dos mesmos, sobretudo, as liberdades fundamentais", o cidadão pertence ao Estado e, como detentor de direitos, garante-os por meio da cidadania.

A lei pode ser utilizada como mecanismo de proteção da liberdade com o direito fundamental. Os indivíduos são livres na medida da liberdade de suas escolhas e decisões, 
sem a coerção ou a imposição de terceiros, com a ausência de obstáculos para o livre exercício do agir conforme os próprios interesses. A lei é apenas um instrumento da proteção da liberdade como direito fundamental. (RAMOS, 2011, p. 46).

A função do sujeito como cidadão na comunidade concretiza-se em fazer valer os preceitos constitucionais e alcançar os objetivos ali intitulados, como a proteção e a garantia dos direitos positivados. Os direitos dos indivíduos dividem-se em direitos básicos à liberdade individual e à vida; direitos políticos; e direitos sociais, os quais oportunizam o bem-estar econômico e social. Caso esses direitos não sejam violados, a cidadania do homem estará resguardada (RAMOS, 2006, p. 82).

A cidadania no modelo liberal ocorre de forma voluntária e temporária. O cidadão assume o seu papel com o uso das ferramentas disponibilizadas pelo governo, na defesa dos seus direitos e liberdades. Diante da diversidade de crenças e valores dos sujeitos, a liberdade dos cidadãos concretiza-se na possibilidade de buscar, entre as concepções existentes na sociedade plural, aquela que melhor agrade aos interesses dos seres humanos, por meio da autonomia da vontade e da individualidade.

Para isso, o Estado precisa atuar de forma isenta de valores éticos, sendo a sua obrigação restrita um agir equitativo, com o propósito de organizar as instituições sociais e políticas e, no máximo, em rever as concepções que os sujeitos julgam ser imprescindíveis para o exercício da cidadania. O posicionamento da atuação estatal nessa vertente ocorre de maneira neutra. Caso o governo exerça suas prerrogativas com ideologias partidárias, interferirá diretamente na autonomia dos indivíduos (RAMOS, 2006, p. 84).

\subsection{A liberdade no modelo republicano}

A liberdade republicana, na concepção de Pettit (1999, p. 41), está ligada à liberdade como ausência de escravidão, ou como ele prefere chamar, de liberdade como não dominação. Essa dominação exemplifica-se na relação entre o senhor e o seu escravo, em que a parte dominante pode interferir de maneira arbitrária na vida da pessoa dominada.

Quando uma pessoa é livre no sentido da liberdade negativa, está isenta de interferências nas coisas que faz - isenta de coerção ou obstrução intencionada -, e isenção significa ausência de interferência. Quando uma pessoa desfruta de não dominação, está isenta de interferências arbitrárias nas coisas que faz, e isenção aqui 
significa que outros são incapazes de interferir em seu caminho (PETTIT, 1999, p. $45)$.

O republicanismo ${ }^{1}$ remete ao ideal aristotélico do homem como animal político, e na sua forma contemporânea mantém valores como a [...] "liberdade política, o autogoverno da comunidade, o civismo e a soberania popular e a participação ativa na comunidade política" (RAMOS, 2006, p. 79). A concepção de liberdade revela-se na cidadania. A cidadania, na visão republicana, concretiza-se nas virtudes cívicas, as quais são indispensáveis para efetivar os direitos e liberdades individuais e para o bom andamento da comunidade. A compreensão política da cidadania republicana divide-se em:

[...] a) análise da liberdade como não dominação b) na dimensão social do viver político do homem; c) o reconhecimento da legitimidade do direito e da igualdade de todos; d) a ideia de comunidade política como autogoverno dos cidadãos na criação de leis que efetivam a liberdade; e) a atuação política do cidadão através da prática de virtudes políticas (RAMOS, 2005, p. 251).

A cidadania e a liberdade só podem existir sob um regime de direito adequado a elas. Nesse sentido, por meio das leis, determina-se a autoridade dos governantes, assim como, por meio da lei, garante-se a liberdade dos cidadãos, com o respeito dos interesses e ideias do povo, com o cuidado para que a lei não se torne um instrumento arbitrário de um determinado indivíduo ou grupo. (PETTIT, 1999, p. 57).

Na liberdade como não dominação, o indivíduo participa ativamente na comunidade e, por meio das virtudes cívicas, ele toma parte das decisões da política a fim de melhor assegurar a sua liberdade e os direitos individuais. O valor da cidadania constitui-se em si mesma, o qual se determina pela liberdade (não dominação) (RAMOS, 2006, p. 85).

Uma relação de dominação na concepção da liberdade republicana significa quando alguém ou um grupo de indivíduos exerce poder de dominação sobre o outro. É a capacidade de interferir de um modo arbitrário em determinados aspectos da vida de outra pessoa, no que ela pode realizar. No republicanismo democrático, para que não haja arbitrariedade no

\footnotetext{
${ }^{1} \mathrm{O}$ republicanismo exposto neste trabalho corresponde ao republicanismo moderno ou neorromano, o qual encontra a sua expressão conceitual adequada para a liberdade como não dominação. "O republicanismo neorromano, sem abandonar o apelo ao autogoverno e à condição do homem como animal político, é mais sensível às demandas da moderna individualidade, destacando a criação de mecanismos institucionais que estimulam e preservam a liberdade individual intimamente ligada à liberdade da comunidade" (RAMOS, 2011, p. 53).
} 
exercício dos que estão no poder, é preciso que exista a constante possibilidade de os membros da sociedade questionarem as decisões do governo (PETTIT, 1999, p. 78 - 91).

Hodiernamente, a atuação do homem, afasta-se cada vez mais dos aspectos humanistas, de valores que visam ao bem comum de toda a sociedade. Diante da polarização coletiva, os indivíduos precisam retomar o sentido do seu papel político na comunidade. $\mathrm{Na}$ democracia, o republicanismo encaixa o seu papel como uma forma de solucionar os problemas atuais, com base na busca pela liberdade, com a revalorização da política e da esfera pública, colocando em prática a democracia contestatória. Para isso, esses preceitos precisam ser construídos desde cedo por meio da educação.

A seguir, expõe-se uma educação pautada no viés liberal e no viés republicano de liberdade, a fim de compreender qual modelo de liberdade na educação pode ser um mecanismo efetivo para a formação de cidadãos que voltam os seus interesses para o bem da comunidade.

\section{A EDUCAÇÃO NA TEORIA LIBERAL E REPUBLICANA}

O tema da liberdade na educação ganhou espaço na política brasileira e nas mídias, com os debates sobre a liberdade de ensinar do professor e o seu limite na forma de apresentar determinados conteúdos nas escolas. Com isso, discutiu-se o Projeto de Lei (PL) 867/2015, intitulado "programa escola sem partido", e a sua inclusão nas diretrizes básicas da educação.

Esse projeto foi anexado ao Projeto de Lei n. 7.180/14, que trata dos Parâmetros Curriculares Nacionais, com a pretensão de definir que os valores e as convicções das famílias dos alunos, ou responsáveis por eles, devem ter precedência sobre a educação escolar no que tange à assuntos relacionados à educação sexual, moral e religiosa, sendo vedadas técnicas ditas subliminares utilizadas pelos professores ao tratar desses temas $\left(\S 1^{\circ}\right.$, do Art. $\left.1^{\circ}\right)$.

O Artigo $3^{\circ}$ do Projeto de Lei "programa escola sem partido" visa regularizar o veto à apresentação em sala de aula de conteúdos que possam entrar em divergência com as convicções religiosas ou morais dos pais ou responsáveis pelos estudantes. A justificativa para a aprovação desse projeto de lei é a proposição de ocorrência de doutrinação política e ideológica por parte de alguns professores, que agem em desfavorecimento dos alunos em razão das suas convicções particulares. 
Uma das normas desse PL, a integrar as diretrizes e bases da educação nacional, seria a neutralidade política, ideológica e religiosa do Estado (Art. $2^{\circ}, \mathrm{I}$ ), o direito dos pais para que os filhos recebam a educação moral de acordo com as suas convicções (Art. $2^{\circ}$, VII), e que os professores não poderão proferir suas preferências partidárias, bem como deverão tratar de forma justa as principais versões de questões políticas, socioculturais e econômicas existentes (Art. $\left.3^{\circ}, \mathrm{I}, \mathrm{IV}\right)$.

O PL 867/2015 foi arquivado no final de 2018 na Câmara dos Deputados, mas tanto este projeto como os demais que tratam desse tema podem ser desarquivados, e o debate sobre a liberdade de ensinar do professor pode ser retomado, tanto que um novo projeto de lei nos mesmos moldes foi apresentado no início de 2019, com apenas alguns ajustes em comparação ao anterior.

A Lei de diretrizes básicas da educação já regulamenta a responsabilidade dos professores no exercício da atividade, além dos demais instrumentos legais existentes no ordenamento jurídico brasileiro, para determinar as regras a serem obedecidas pelo professor no ambiente escolar.

O texto constitucional brasileiro $(\mathrm{CF} / 88)$ define como competência privativa da União legislar sobre as diretrizes básicas da educação nacional (Art. 22, XXIV), como competência comum de todos os entes federativos proporcionar os meios de acesso à

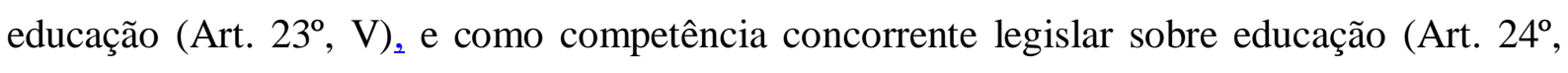
IX). Assim, a responsabilidade do Estado restringe-se a legislar sobre o tema para visar ao pleno desenvolvimento do ser humano e do seu preparo como cidadão.

A forma de governo mais eficaz para transmitir a educação para todos é a democracia, pois tem como preceito o debate livre. A liberdade de opinião independente do posicionamento político do governo. (HAYEK, 1983, p. 126). A alçada do Estado não diz respeito à forma como o professor deve ou não ensinar determinado assunto, pois o ensino precisa ser pautado pela liberdade e pelo pluralismo de ideias por meio do debate livre. Esse debate pode ser apresentado pelo professor livremente, desde que respeitado o conteúdo mínimo a ser abrangido, o qual é estipulado pelo currículo nacional e pelas normas da escola.

O conhecimento revela-se como um bem supremo na sociedade em razão da sua influência e dos benefícios que pode trazer ao ser humano e à coletividade. Nesse sentido, Friedman (1988, p. 95) afirma que a educação das crianças contribui para o seu bem-estar e o da comunidade na construção de uma sociedade democrática, que só é possível mediante um 
mínimo de educação garantida e com a aceitação de certos valores pela maioria dos indivíduos.

A apresentação de questões que possam contrariar as convicções individuais dos alunos e dos seus pais faz parte do processo educacional, e da construção da cidadania em vista das diversas concepções existentes na sociedade sobre o mesmo assunto. A exposição de temas nas suas variadas vertentes contribui para a pluralidade do debate e do ensino, na busca do bem comum, para atender o fim democrático.

Ao instituir a educação obrigatória, o governo se responsabiliza por definir quais os conteúdos que deverão ser inseridos no ensino nacional. A educação pública, na visão de John Stuart Mill (2000, p. 160-161), não é positiva, pois, ao estar concentrada nas mãos do Estado, ela pode ser utilizada como artifício para moldar as pessoas conforme o interesse dos que estão no poder, e que tornam as pessoas iguais umas às outras. Para Mill, uma educação dirigida por valores pré-definidos e estabelecida pelo governo confere ameaça à liberdade. Nesse sentido, ele considera importante a individualidade, bem como a diversidade das opiniões na educação.

A fim de evitar que o Estado exerça uma influência coercitiva sobre a opinião dos alunos, Mill (2000, p. 162) entende que a função estatal no ensino:

[...] deveria limitar-se exclusivamente aos fatos e à ciência positiva. Os exames
sobre religião, política ou outros tópicos controversos não se baseariam na
verdade ou falsidade das opiniōes, mas no fato de tal ou tal opinião ser
professada, segundo tais fundamentos, por tais ou quais autores, escolas ou
igrejas. Sob esse sistema, a geração não estaria pior, em relação a todas as verdades
controversas, do que está agora; [...] o Estado simplesmente cuidaria que não fosse
instruída como clero ou como dissidente. Nada a impediria de aprender religião, se
seus pais desejassem, nas mesmas escolas em que aprendessem todo o resto. Todos
os esforços do Estado para influenciar as conclusões controversas são nocivas, mas
o Estado pode perfeitamente se oferecer para verificar e atestar que uma pessoa
possui o conhecimento necessário para tirar suas próprias conclusões a respeito de
qualquer assunto digno de nota. (MILL, 2000, p. 162, grifo nosso).

Dessa forma, Mill apresentava a possibilidade de permitir que alunos aprendessem assuntos que envolvessem política e religião nas escolas. Embora sejam temas controversos, dizem respeito à sociedade nas suas múltiplas esferas. Os conteúdos expostos em sala de aula, nas suas distintas vertentes, contribuem para o acesso à informação e à formação da cidadania nos alunos. 
Com isso, as crianças receberiam as mesmas oportunidades de acesso ao conhecimento que qualquer outra pessoa. Ao ensinar livremente, com a apresentação de posicionamentos opostos sobre um mesmo assunto, os professores promovem o respeito às diferentes opiniões nos alunos, e a formação de cidadãos livres, capazes de conviver com a diversidade e respeitar o próximo.

[...] Na verdade, formam a instrução particular de um cidadão a parte prática da educação política de um povo livre, na medida em que os retiram do círculo estreito do egoísmo pessoal e familiar, e os acostumam a compreender os interesses gerais, a tratar das questões coletivas; habituam-nos a agir por motivos públicos ou semipúblicos, e a orientar sua conduta por vias que os unem, em vez de os isolar. Sem esses hábitos e essas faculdades, nunca se pode criar nem conservar uma constituição livre, tal como o mostra a tão frequente natureza transitória da liberdade política nos países onde a constituição não repousa sobre uma base suficiente de liberdades locais (MILL, 2000, p. 166, grifo nosso).

O Estado, ao permitir o debate de temas relacionados às esferas da sociedade por meio da liberdade do discurso na educação, mesmo quando o assunto diverge do posicionamento dos pais ou responsáveis, corrobora o processo educacional democrático na pluralidade de aprendizagem e na formação do indivíduo político, que será capaz de discutir os problemas da sua comunidade e contestar as decisões dos representantes políticos.

A condição de liberdade da criança é limitada devido a sua característica de estar em desenvolvimento físico, intelectual e cognitivo. O encargo pela garantia do seu bem-estar e dos seus direitos recai sobre os seus pais ou responsáveis, os quais também não detêm o controle da vida e da liberdade dos filhos de forma incondicional (HAYEK, 1983, p. 362).

Os liberais do século XIX confiaram no poder da transmissão do conhecimento e, assim, defendiam o acesso à educação para todas as classes, pois acreditavam no seu poder para a resolução dos problemas da sociedade. Para eles, porém, a educação precisava ser norteada livre de valores estereotipados, sob pena de subversão à própria liberdade (HAYEK, 1983. p. 363)._Com base nos valores liberais, a educação sucede de forma livre, sem restrições. A promoção do raciocínio crítico contribui para formar cidadãos capazes de dialogar com as instituições, atuar em cooperação com o próximo, além de vivenciar a diversidade e o respeito.

Somente com o uso da razão crítica é que se pode atingir a liberdade, a partir da compreensão do necessário e do contingente. Para Berlin (1969, p. 149), o estudante, a respeito da matéria ensinada, [...] "absorveu a pauta em seu próprio sistema; compreendendo- 
a, identificou-se com ela, transformou-a de um impedimento à livre atividade em um elemento da própria atividade". As paixões e preconceitos estão carregados de mitos e ilusões, portanto, para ele, o conhecimento liberta o homem dos seus medos irracionais, ao compreender por meio da razão o conteúdo apresentado.

Contudo, a visão de uma educação neutra demonstra-se inviável de ser posta em prática. O curso da história, da vida humana, dos seus aspectos e particularidades, não é isento de posicionamentos e ideologias. A educação pautada em discurso neutro, embora seja um ideal a ser aplicado, demonstra-se ilusória, pois cada decisão do ser humano na evolução da sociedade está carregada de valores morais ou políticos.

O Estado liberal, como pressuposto do Estado neutro, institui a não intervenção estatal como base da liberdade. O modelo liberal propõe uma educação restrita aos ensinamentos das matérias e dos direitos civis dos cidadãos.

Nesse sentido, sem avaliar a existência de ideologia no discurso dos professores, percebe-se que, nas democracias atuais, há uma educação com pressupostos liberais, não em sua totalidade, em que os alunos recebem os ensinamentos escolares com base na perspectiva da autonomia da vontade do cidadão, na busca dos interesses individuais. A educação com conjecturas liberais não envolve necessariamente uma preocupação com os negócios coletivos, bem como não contribui para a formação de cidadãos ativos nos assuntos da comunidade, seja de uma forma contestatória ou participativa (PETERSON, 2009, p. 11).

A despeito disso, a educação, no liberalismo, pode ser interpretada como um mecanismo disponível para a convivência social, que deixa os seres humanos livres para suas escolhas, apenas com a imposição do cumprimento das leis, sem a ingerência dos valores a serem levados em conta na vida social. Todavia, destaca-se a importância do respeito, da cooperação, da individualidade do ser humano, sem que sejam apresentados valores para uma formação cidadã (RAMOS, 2006, p. 89).

De outro modo, a abordagem da educação no modelo republicano corrobora a necessidade de um cidadão com exercício ativo na comunidade. Assim, para o desenvolvimento de sujeitos conhecedores dos valores e virtudes cívicas imprescindíveis à construção da cidadania, com base na liberdade como não dominação, a educação compõe-se de valores intrínsecos relacionados aos seus ideais.

Pautada pela virtude cívica, a educação envolve a valorização dos valores republicanos para torná-los parte da vida dos indivíduos. As instituições educacionais podem, 
por meio da educação, [...] "enraizar hábitos republicanos nas práticas sociais e políticas, adequadas ao espírito da liberdade como não dominação. Ela torna-se, então, cívica, porque forma virtudes que ajudam a sustentar e a desenvolver uma cidadania republicana." (RAMOS, 2006, p. 88).

Diz-se que até mesmo o currículo educacional ajustado conforme o ideal republicano não pode ser considerado um documento neutro, pois, nesse modelo, estaria carregado de determinadas crenças e valores (SNIR, EYLON, 2016, p. 5). Conclui-se, portanto, que a educação republicana não está isenta do agir indevido dos que têm a intenção de usar o ensino como mecanismo de manipulação. O professor, embora em posição superior à do aluno, não atua com dominação, mas com base na busca da construção do coletivo.

A garantia da liberdade individual como não dominação, na concepção de Skinner (1999, p. 95), envolve o conceito republicano de liberdade e, nesse aspecto:

[...]_o Estado tem o dever não só de liberar seus cidadãos dessa exploração e dependência pessoal, como de impedir que seus próprios agentes, investidos de uma pequena e breve autoridade, ajam arbitrariamente no decorrer da imposição das regras que governam nossa vida comum. (SKINNER, 1999, p. 95).

O ensino republicano permite conceber a escola como um local de liberdade, no sentido do pensar livremente, sem imposições arbitrárias de temas que englobam a sociedade, mas com a construção do aluno como indivíduo político, o qual deve pensar no todo. Ainda, os alunos no modelo republicano questionam os ensinamentos impostos, não no sentido de desafiar e desrespeitar o professor, mas na intenção de promover o debate.

Neste ínterim, depreende-se que, para a construção da cidadania, é preciso fornecer uma gama de percepções das diversas matérias e temas que envolvem a sociedade, como aspectos econômicos, sociais, ambientais, a fim de promover a ampliação do conhecimento para que o aluno desenvolva um raciocínio capaz de compreender o sistema geral e contestar quando achar pertinente. A ideia é o desenvolvimento de habilidades para considerar vários pontos de vista e atuar como membro da sociedade, com base no interesse coletivo.

No ensino com valores republicanos, os alunos comprometem-se em considerar as opiniões dos seus pares, em trabalhar em conjunto e encontrar uma solução plausível para os problemas apresentados em sala de aula que sejam favoráveis ao grupo. 
[...] O modelo resultante é muito semelhante ao da democracia deliberativa [...] em que a cidadania participativa, incluindo seus aspectos contestatórios, é realizada através de discussões públicas racionais, na qual a pluralidade de visões e opiniões podem ser expressadas, desde que os argumentos apresentados sejam relevantes e acessíveis a todos. (SNIR, EYLON, 2016, p 12. Tradução livre).

Nesse sentido,

[...] A ligação entre cidadania republicana e deliberação é importante para Pettit: para que as leis e políticas sejam fundamentadas em razões sólidas, ele escreve, elas devem confiar em processos abertos de deliberação. Isso liga o republicanismo cívico à democracia deliberativa, que não é baseado em um compromisso entre as partes que se apegam a opiniões preexistentes, mas, sim, nas partes que decidem de acordo com o melhor argumento (SNIR, EYLON, 2016, p. 5. Tradução livre).

Analisada pelo viés republicano, a educação concentra seu interesse na construção da cidadania para a democracia. A liberdade como não dominação do republicanismo deve ocorrer tanto entre os indivíduos, como na relação entre Estado e indivíduo.

Ao referir-se aos cidadãos, Pettit (1999, p. 160 - 161) não engloba as crianças, pois entende que elas são incapazes de desempenhar um papel determinante nos assuntos públicos. $\mathrm{Na}$ sua visão, as crianças precisam ser submetidas às disciplinas inerentes da escola para o curso normal do seu processo de desenvolvimento na educação, a fim de que, quando adultas, possam desfrutar da liberdade com não dominação: [...] "no ponto de vista republicano sugeriria que as crianças deveriam desfrutar da intensidade da não-dominação, no sentido de ser protegida, assim como qualquer outra pessoa, contra as arbitrariedades do poder." (PETTIT, 1999, p. 161, tradução livre).

Embora exista diferença entre adultos e crianças no que concerne à atuação cidadã, as crianças devem ser levadas em consideração. O ideal é que sejam tratadas conforme a sua condição de ainda em desenvolvimento.

[...] Teorias educacionais modernas, especialmente aquelas associadas a educação progressista, afirmam que as crianças são capazes de algum grau de autonomia de pensamento e responsabilidade; as crianças devem ser tratadas como pessoas que pensam ativamente no presente, não apenas como um potencial a ser realizado no futuro (SNIR, EYLON, 2016, p. 11. Tradução livre).

No caso do melhor interesse das crianças, há a competência da família, do Estado e da sociedade para sua proteção. A Constituição Federal de 1988, em seu Artigo 227, caput, disciplina que é dever de todos assegurar à criança, com absoluta prioridade, o direito à 
liberdade, à educação, à vida, à saúde, à alimentação, ao lazer, à cultura, à dignidade, ao respeito, entre outros direitos, inclusive à proteção contra qualquer forma de exploração, negligência e opressão com base no princípio de proteção integral.

Portanto, para a proteção integral das crianças de qualquer tipo de dominação nas escolas, os pais e professores devem canalizar suas energias para a promoção dos direitos individuais e fundamentais para o melhor interesse delas. A educação torna-se instrumento de promoção de hábitos republicanos na sociedade, sem a ocorrência do modo arbitrário.

As instituições precisam contribuir para a educação moral dos cidadãos, com o respeito dos seus direitos individuais, com a proteção da propriedade privada e da autonomia do indivíduo, e incentivá-los para atuar na comunidade, com decisões e votos, com a proteção de seus direitos e opiniões, de modo que atuem efetivamente na mais alta função na sociedade. (CONSTANT, 1985, p. 25).

Mesmo sem o status de cidadãos na visão de Pettit, entende-se imprescindível a proteção da liberdade das crianças para a formação da cidadania. Nesse sentido, a escola, como instituição, deve intervir no caso de imposições arbitrárias, mas, ao mesmo tempo, viabilizar uma educação livre para a concretização do desenvolvimento da aprendizagem.

Nesse sentido, muito embora Philip Pettit não tenha feito uma abordagem profunda da liberdade como não dominação no ambiente estudantil, ela pode ser utilizada de maneira eficiente para fornecer uma base para a construção de cidadãos com virtudes cívicas, que, só por meio dessas virtudes, poderão alcançar o status de liberdade sem interferências, e a promoção dos preceitos constitucionais positivados, tanto nos direitos individuais como nos direitos sociais.

\section{CONCLUSÃO}

Por todo o exposto, conclui-se que o ensino baseado na neutralidade de opiniões demonstra-se inviável, pois os acontecimentos ocorridos na história da humanidade, as lutas, as guerras foram construídas com posicionamentos políticos, partidários e ideológicos.

Embora o intuito de promover a educação com base na construção da cidadania com virtudes cívicas tenha certo caráter valorativo, a educação pautada nesse ideal republicano propõe um ambiente livre de imposições, com a viabilidade de aprendizagem com base na pluralidade de conceitos e debates. 
Na visão de Philip Pettit, as crianças não exercem a cidadania nas mesmas condições que os adultos devido à capacidade contestatória nos assuntos da sociedade, mas pode-se dizer que a educação com valores republicanos incentiva desde cedo o envolvimento dos alunos nas discussões para encontrar soluções voltadas ao melhor interesse de todos. O livre debate em sala de aula faz parte do processo de desenvolvimento da educação, do raciocínio lógico, inclusive da fase de construção da formação cidadã.

Portanto, em um Estado Democrático de Direito, que possui como um dos seus fundamentos a cidadania, a liberdade como direito fundamental e a educação como direito social, o ensino baseado em conceitos neutros, conforme o proposto recentemente nos debates políticos, não se demonstra possível.

Apresentada de forma contextualizada aos alunos, a educação compreende acontecimentos históricos, sociais e políticos. A sociedade precisa tomar para si a responsabilidade dos assuntos que influenciam a construção e a permanência de uma sociedade democrática, a fim de contestar os projetos de lei apresentados pelo governo. A escola deve permanecer um ambiente livre, pautado nos valores constitucionais, com base na liberdade de ensinar e aprender pelo pluralismo de ideias.

\section{REFERÊNCIAS}

BERLIN, Isaiah. Quatro ensaios sobre a liberdade. Trad. de Wamberto Hudson Ferreira. Brasília, Editora Universidade de Brasília, 1981, c1969.

BONAVIDES. Paulo. 2001. Teoria Constitucional da Democracia Participativa: Por um direito Constitucional de luta e resistência, por uma nova Hermenêutica, por uma repolitização da legitimidade. Malheiros Editores 2001.

BRASIL. Constituição (1988). Constituição da República Federativa do Brasil de 1988. Brasília, DF: Presidência da República. Disponível em:

http: //www.planalto.gov.br/ccivil 03/constituicao/con stituicao.htm. Acesso em: 12 mar. 2019.

BRASIL. Projeto de Lei N. 867, de 2015 (Câmara dos Deputados). Inclui, entre as diretrizes e bases da educação nacional, o "Programa Escola sem Partido". Brasília. Disponível em: https: / / wwW. camara.leg.br/proposicoesWeb/fichadetrami tacao?idProposicao=1050668. Acesso em: 12 de mar. 2019.

CHAUÍ, Marilena. O Que é Política? In: NOVAES, Adauto. O Esquecimento da Política. Rio de Janeiro: Agir, 2007. 
CONSTANT, Benjamin: Da liberdade dos antigos comparada à dos modernos, Revista de Filosofia Política, n.2, 1985, pp. 9-25.

FRIEDMAN, Milton. Capitalismo e Liberdade. São Paulo: Nova Cultural, 1988.

HAYEK, Friedrich A. Os fundamentos da liberdade. Ed Visão. 1983.

MILL, John Stuart. A Liberdade Utilitarismo. Martins Fontes. 2000.

PETERSON, Andrew. 2009. Civic republicanism and contestatory deliberation: Framing pupil discourse within citizenship education. British Journal of Educational Studies 57(1): $55-$ 69.

PETTIT, Philip. Republicanismo. Una teoría sobre la libertad y el gobierno. Editorial Paídos Iberica Ediciones, 1999. traducción, Toni Doménech.

RAMOS, Cesar Augusto. O liberalismo político e seus críticos. Crítica Revista de Filosofia, Londrina, v. 10, n. 32, p. 229-264, out. 2005.

RAMOS, Cesar Augusto. A cidadania como intitulação de direitos ou atribuição de virtudes cívicas: liberalismo ou republicanismo? Síntese - Ver. De Filosofia. V. 33, n. 105. 2006: $77-115$.

RAMOS, Cesar Augusto. O modelo liberal e republicano de liberdade: uma escolha disjuntiva? 2011.

SKINNER, Quentin. A Liberdade antes do liberalismo. Trad. Raul Fiker, São Paulo: Editora Unesp, 1999, p. 95

SNIR, Itay; EYLON, Yuval. Civic Republicanism and Education: Democracy and Social Justice in School. British Journal of Education Studies. Published online. September 2016. 